\title{
Modelagem Matemática do Ângulo de Incidência em Grãos Armazenados
}

\author{
Marilia Vasconcellos \\ Depto. de Ciências Exatas e Engenharias, DCEEng, UNIJUÍ \\ Rodovia RS 342, $N^{o}$ KM 39 - CEP 98900000 - Santa Rosa(RS) \\ E-mail: marilia.vasconcellos@unijui.edu.br
}

\begin{abstract}
Resumo: A produção de grãos é um dos principais segmentos do setor agrícola no Brasil e no mundo. Sendo assim, é de grande importância a realização de estudos que possam contribuir para garantir a qualidade dos produtos estocados por longos períodos. Visando a conservação dos grãos armazenados, utiliza-se nos armazéns um método de controle que é a aeração Esta pesquisa propõe aprofundar ainda mais o estudo sobre a distribuição do fluxo do ar em armazéns sob o efeito da não homogeneidade e da anisotropia em grãos de arroz, soja, milho e trigo. A anisotropia foi relacionada com o ângulo de incidência mais provável que os grãos podem ocupar na massa de grãos, visando assim desenvolver sistemas de aeração mais eficazes.
\end{abstract}

\section{Introdução}

A agricultura no Brasil é, historicamente, umas das principais bases da economia do país. No Brasil, a produção brasileira de grãos no período de 2011/12 chegou a quase 157,8 milhões de toneladas, sendo que desses, 68,75 milhões de toneladas são de grãos de soja, conforme a Companhia Nacional de Abastecimento a CONAB. Apesar disso, o Brasil, é campeão em desperdício, apresentando elevadas perdas agrícolas que se devem a uma série de fatores que são facilmente localizados, muitos deles de origem técnica.

Os grãos armazenados são afetados por fatores bióticos, como micróbios, insetos, ácaros, roedores e fatores abióticos, como umidade e temperatura. A temperatura dos grãos e o teor de umidade são os dois fatores mais importantes que afetam o crescimento e atividade destes organismos biológicos.

A técnica mais utilizada para garantir um armazenamento seguro, é a aeração, este processo, inibe o desenvolvimento de insetos e da microflora, além de preservar a qualidade dos produtos, diminuindo o gradiente de temperatura na massa de grãos e consequentemente, minimizando a migração da umidade.

A aeração consiste, na movimentação forçada de ar ambiente adequado através da massa de grãos, com o objetivo geral de diminuir e uniformizar a temperatura, proporcionando a essa massa condições favoráveis para conservação da qualidade durante um período de tempo prolongado [4]. Quando o ar é forçado a passar através de uma camada espessa de material agrícola, a queda de pressão provocada pela resistência ao fluxo de ar desenvolve-se como um resultado da energia perdida por atrito e turbulência.

A predição na resistência do fluxo de ar, já vem sendo estudada nos últimos 70 anos e é fundamental para o projeto de sistemas de secagem e aeração mais eficiente. Por essas razões, o objetivo deste trabalho é analisar os ângulos de maior incidência que predominam nos grãos em um sistema de armazenagem.

Para isso este artigo se organiza de tal forma: na Seção 2 é apresentada a modelagem matemática proposta no trabalho, na Seção 3 é descrito os métodos utilizados para a obtenção dos dados experimentais, na Seção 4 são apresentados os resultados e as conclusões obtidas e por fim apresentam-se as referências bibliográficas na Seção 5. 


\section{Modelo Matemático}

O modelo matemático usado neste trabalho, para a simulação da corrente de ar nos meios particulados para duas e três dimensões, é descrito pelo sistema de equações de continuidade, equação (1), e de movimento, equação (2)

$$
\begin{gathered}
\text { div } \quad \vec{V}=0 \\
\text { grad } P=\alpha \vec{V}+\beta|\vec{V}| V
\end{gathered}
$$

onde $\mathrm{V}$ é o vetor velocidade em $\mathrm{m} / \mathrm{s}$, $\mathrm{P}$ é a pressão em $\mathrm{Pa}, \alpha$ e $\beta$ são constantes que dependem do tipo de grão que forma o meio particulado.

Em problemas que envolvem a distribuição do fluxo do ar em meio à massa de grãos, a equação (2) é substituída pela dependência empírica $V=f(\operatorname{gradP})$, que representa a equação não linear do movimento. Na maioria das equações, o gradiente de pressão é expresso como uma função de velocidade através da parábola de segunda ordem sem um termo livre [5]. Para o caso $2 \mathrm{D}$ e 3D, a equação (2) pode ser escrita na forma simplificada

$$
V=-K \cdot \operatorname{grad} \quad P
$$

onde $K$ é o tensor de permeabilidade para meio anisotrópico. Para meio isotrópico não homogêneo $K=K(x, y, z)$ é escalar. Expressando o tensor de proporcionalidade $\mathrm{K}$ :

$$
K=\frac{1}{\alpha+\beta|V|}
$$

se $\mathrm{x}, \mathrm{y}$ e $\mathrm{z}$ são direções principais aos autovalores da matriz $\mathrm{K}$, então o tensor tem forma diagonal. Assim, as componentes de velocidades para o caso tridimensional podem ser expressas em $u, v$ e $w$ na forma:

$$
u=-K_{x} \frac{\partial P}{\partial x} \quad v=-K_{y} \frac{\partial P}{\partial y} \quad w=-K_{z} \frac{\partial P}{\partial z}
$$

onde a coordenada y em metros corresponde à direção vertical e as coordenadas x e z estão localizadas no fundo do silo. Substituindo a equação (4) na equação de continuidade (1), obtemos a equação diferencial parcial não linear para pressão

$$
\frac{\partial}{\partial x}\left(-K_{x} \frac{\partial P}{\partial x}\right)+\frac{\partial}{\partial y}\left(-K_{y} \frac{\partial P}{\partial y}\right)+\frac{\partial}{\partial z}\left(-K_{z} \frac{\partial P}{\partial z}\right)=0
$$

onde $K_{x}, K_{y}$ e $K_{z}$ são os coeficientes de permeabilidade nas direções principais.

As condições de contorno para o problema considerado têm a seguinte forma

$$
P=P_{e}
$$

(Condição de Dirichlet para entrada e saída do ar)

$$
n \cdot K \cdot \operatorname{grad} \quad P=0
$$

(Condição de Neumann nas paredes e chão do silo). 
A equação (6) juntamente com as condições de contorno, equação (7) e equação (8), descreve a distribuição de pressão e velocidade em uma secção transversal de um armazém de grãos, aerados sob condições não uniformes e anisotrópicas.

\section{Estudo Experimental}

O formato, as dimensões, a integridade física, a integridade biológica, as impurezas e/ou materiais estranhos e a umidade são fatores que podem interferir no posicionamento dos grãos e consequentemente no ângulo formado por eles, pois conferem adesividade à superfície dos grãos [2].

O estudo foi realizado para grãos de trigo, milho, arroz (em casca) e soja, no período de agosto de 2011 a dezembro de 2011. A Tabela 1 apresenta as características de grãos obtidos pelo Laboratório de Medidas Físicas para Modelagem Matemática, Universidade Regional do Noroeste do Rio Grande do Sul - UNIJUI, Brasil. Os grãos utilizados nos testes apresentaram um teor de umidade de $11-13 \%$ e impurezas foram inferiores a $2 \%$.

\begin{tabular}{|l|l|l|l|l|}
\hline Sementes & Soja & Milho & Arroz & Trigo \\
\hline $\begin{array}{l}\text { Peso de 100 sementes } \\
(\mathrm{Kg})\end{array}$ & 0,012 & 0,027 & 0,002 & 0,003 \\
\hline Teor de umidade (\%) & 13 & 11 & 11,7 & 11,5 \\
\hline $\begin{array}{l}\text { Densidade dos grãos } \\
\left(\mathrm{Kg} / \mathrm{m}^{3}\right)\end{array}$ & 1170 & 1300 & 1220 & 1210 \\
\hline $\begin{array}{l}\text { Densidade da massa } \\
\left(\mathrm{Kg} / \mathrm{m}^{3}\right)\end{array}$ & 670 & 730 & 540 & 670 \\
\hline Porosidade da camada & 0,43 & 0,44 & 0,56 & 0,45 \\
\hline
\end{tabular}

Tabela 1. Principais propriedades das amostras dos grãos utilizados nos experimentos.

Os experimentos foram desenvolvidos da seguinte forma: os grãos de soja, milho, trigo e arroz, foram depositados separadamente em uma câmara de grãos, um recipiente de acrílico em forma de cubo, com 0,4 m de arestas, na base da câmara de grãos, existe uma chapa de acrílico perfurada com 1600 furos que sustenta os grãos e permite a passagem do ar, fazendo o papel de um "fundo falso", conforme a Figura 1, quando a câmara de grãos estava cheia de grãos, adicionou-se água.

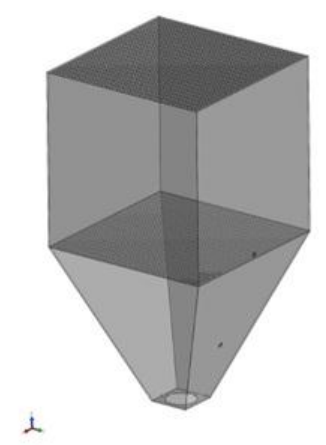

Figura 1. Câmara de grãos, [6].

Uma vez que o sistema estava completo, com grãos e água, a câmara foi transportada para um freezer horizontal, onde ficou por dois dias consecutivos, para que a água solidificasse e o sistema não sofresse mais mudanças, ficariam conservadas as características interna do sistema possibilitando assim, uma análise do comportamento dos grãos no interior da câmara. 
Para uma análise mais precisa dos grãos no interior da massa granular, observando a influência da não homogeneidade na massa de grãos, o material solidificado foi retirado da câmara de grãos e seccionado, em camadas a cada $10 \mathrm{~cm}$ e fotografados, conforme a Figura 2, com o microscópio digital Dino Lite AM-313T (ANMO Eletronic Corporation, Compex, Brasil), um aparelho digital portátil que apresenta resolução de 640x480, interface USB 2.0, ampliação continua e recurso de medição.

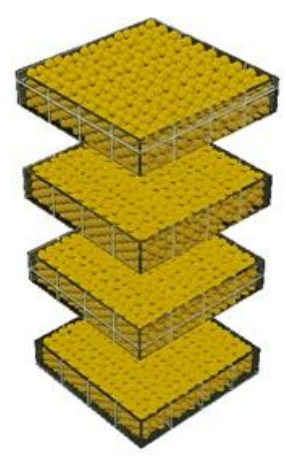

Figura 2. Camadas de $10 \mathrm{~cm}$.

Depois de obtidas, as fotos das camadas eram direcionadas para o software Dino Capture que acompanha o microscópio digital Dino Lite, o software possui o recurso de medida precisa, no qual se obteve, com alta precisão, a medida dos ângulos, conforme a Figura 3.

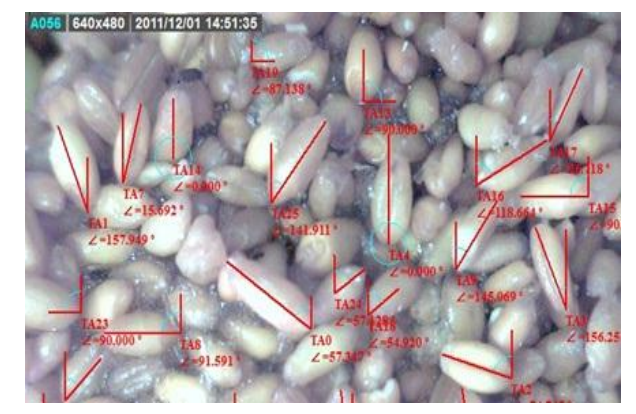

Figura 3. Ângulos em relação ao fluxo em grãos de trigo.

\section{Resultados}

As características físicas dos produtos agrícolas são de suma importância para os estudos envolvendo transferência de calor e massa e movimentação do ar em produtos granulares. Outras aplicações significativas do conhecimento das características dimensionais de frutos e grãos estão associadas à elaboração de projetos de unidades de processamento e ao dimensionamento de equipamentos de secagem, separação, armazenagem e classificação [7].

Os resultados obtidos experimentalmente referem-se ao comportamento da massa de grãos de soja, milho, trigo e arroz (em casca), simulados em uma câmara, para a análise do posicionamento dos grãos, verificando os ângulos de maior incidência que variam de $\phi=0^{\circ}-90^{\circ}$.

Os dados obtidos experimentalmente foram agrupados e plotados através de uma distribuição por frequência.

Analisado a distribuição angular em relação ao fluxo, percebe-se que a cultura de milho, conforme a Figura 4 assemelha-se da frequência esperada, o que a caracteriza por uma distribuição normal. Através da análise pode-se concluir que o ângulo de maior incidência para 
essa cultura é de $50,89^{\circ}$ graus com um coeficiente de variação de 0,52 . Para a cultura de soja, pode-se estimar que o ângulo de maior incidência em relação ao fluxo é de $46,02^{\circ}$ graus com coeficiente de variação de 0,52, conforme a Figura 5.

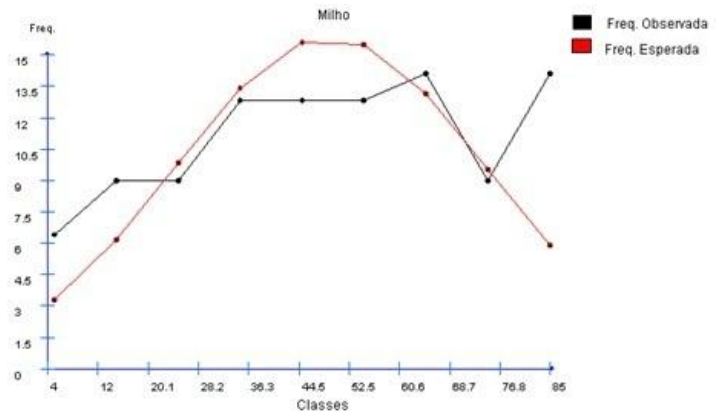

Figura 4. Distribuição por frequência do ângulo em relação ao fluxo em grãos de milho.

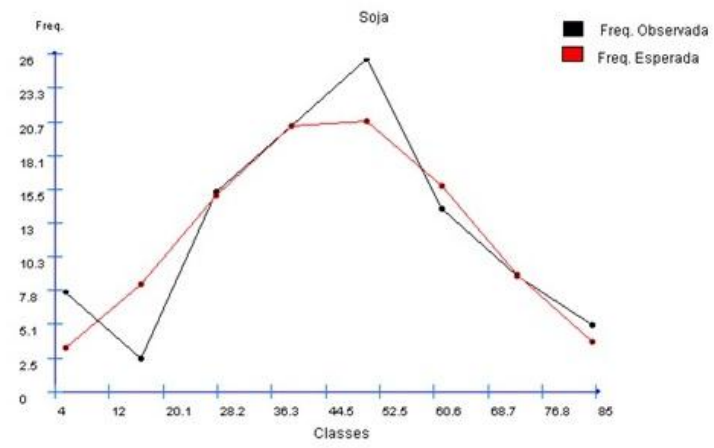

Figura 5. Distribuição por frequência do ângulo em relação ao fluxo em grãos de soja.

Segundo Khatchatourian (2009), o fator anisotrópico é definido pela relação $\frac{K_{x}}{K_{y}} \mathrm{e}$ depende do número de Reynolds (por meio da velocidade do ar e da morfologia do grão) e representa uma característica dinâmica do fluxo do ar, Assim, pode ser nomeado fator anisotrópico "aerodinâmico" ou "hidrodinâmico". Até mesmo para diferentes massas de grãos os fatores de anisotropia podem ser iguais em diferentes velocidades correspondentes.

A Figura 6 apresenta a relação, entre ângulo e fator de anisotropia para dos dados observados, pode ser dada pela equação de segunda ordem com um valor de $\mathrm{R}^{2}$ de 0,96 .

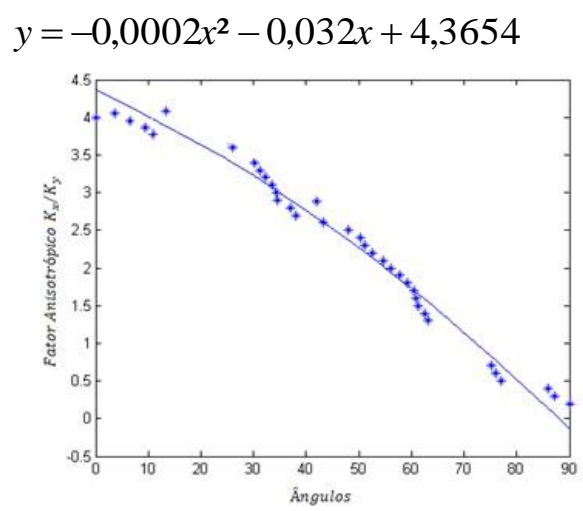


Figura 6. Relação entre ângulo de incidência e fator de anisotropia.

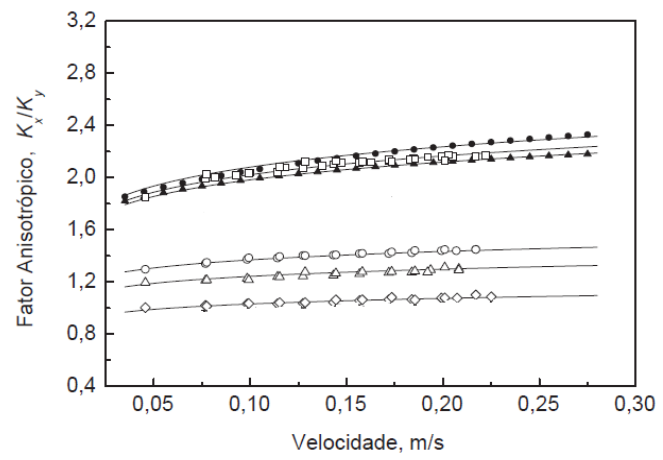

Figura 7. Relação entre permeabilidade horizontal e vertical para vários tipos de sementes: • linhaça, $\boldsymbol{\Delta}$ aveia, $\square$ arroz, O milho, $\Delta$ trigo, $\diamond$ soja.

As simulações mostram que há uma diferença entre fluxos de ar para meios isotrópicos e anisotrópicos. Esta diferença depende do tipo de grão, (valor do fator de anisotropia), e da localização da entrada do ar. A relação dos fatores de permeabilidade horizontal e vertical depende da forma do grão e aumenta significativamente como desvio da forma esférica. Esta relação cresce com um aumento no valor da velocidade, e no valor do ângulo de incidência. $O$ estudo do efeito da anisotropia em armazéns é de suma importância, pois pode ajudar engenheiros a projetarem sistemas de aeração mais eficientes e adequados às dimensões das estruturas de armazenamento, garantido assim o bom funcionamento do sistema.

\section{Referências Bibliográficas}

[1] Conab (2012). Companhia Nacional de Abastecimento. www.conab.gov.br.

[2] Elias, M. C. (2003). Armazenamento e Conservação de Grãos. Universidade Federal de Pelotas Faculdade de Agronomia "Eliseu Maciel", Pelotas, 82p.

[3] Khatchatourian, O. A; Toniazzo, N. A; Gortyshov, Y. F. (2009). Simulation of Airflow in Grain Bulks under Anisotropic Conditions. Biosystems Engineering, 104, pp. 205 - 215.

[4] Pereira, J. A. M. (1995). Aeração de Grãos: Fundamentos e Manejo. Centro Nacional de Treinamento de Armazenagem - Centreinar, Viçosa.

[5] Scheidegger A. E. (1960). The Physics of flow through Porous Media. University of Toronto Press, Toronto.

[6] Tozinni, F. (2010). Estudo do Escoamento do Ar em Massa de Grãos sob Condições Anisotrópicas. Ijuí, Rio Grande do Sul: Imprensa Universitária, Universidade Regional do Noroeste do Rio Grande do Sul - UNIJUI. 64p. Dissertação de Mestrado.

[7] Weber, E. A. (1995). Excelência em Beneficiamento e Armazenagem de Grãos. Ed. Salles. 